\title{
Commentary: Benign cardiac papillary fibroelastomas: Beware the "divergents"
}

\author{
David D. Yuh, MD, FACS, FACC
}

From the Department of Surgery, Stamford Hospital, Stamford, Conn

Disclosures: Author has nothing to disclose with regard to commercial support.

Received for publication Oct 20, 2018; accepted for publication Oct 21, 2018; available ahead of print Nov 30, 2018.

Address for reprints: David D. Yuh, MD, FACS, FACC, Department of Surgery, Stamford Hospital, Stamford, CT (E-mail: DYuh@stamhealth.org).

J Thorac Cardiovasc Surg 2019;157:e129-30

$0022-5223 / \$ 36.00$

Copyright (C) 2018 by The American Association for Thoracic Surgery

https://doi.org/10.1016/j.jtcvs.2018.10.098

The rarity, indolent progression, and "benign" classification of most primary cardiac tumors has likely contributed to the lack of understanding of their histogenesis, biologic behavior, and treatment relative to other more prevalent noncardiac tumors. Because they are viewed more as clinical curiosities than as bona fide cardiac pathologies, with the primary treatment consisting of surgical excision, the literature concerning papillary fibroelastomas has largely consisted of clinical series and case reports of unusual locations and manifestations, ${ }^{1,2}$ such as the report in this issue of the Journal by Popovic and colleagues. ${ }^{3}$ What distinguishes this case report from others, however, is its description of recurrence of a valve-based (aortic valve) papillary fibroelastoma to a "distant" nonvalvular site (left ventricle). This finding is inconsistent with the notions that these lesions are benign and may not even be true neoplasms but rather hamartomas or reactive changes of normal tissue. Importantly, it implies that, like most other neoplasms, the biologic behavior and metastatic potential of papillary fibroelastomas may actually vary on a spectrum.

Playing devil's advocate, one cannot help but speculate that, rather than a distant recurrence, this was an atypical asynchronous or metasynchronous multifocal presentation of papillary fibroelastoma, with microscopic foci of fibroelastoma cells in the left ventricle that could not be visualized during the primary resection of the valvular lesions but later developed into the impressive tumors nicely depicted in this report. Although multiple tumors are uncommon with papillary fibroelastoma, ${ }^{4}$ an incidence as great as $6 \%$ was noted in one large study. ${ }^{5}$ Certainly, multicentricity is also observed with myxomas, another benign cardiac tumor, and is associated with a more aggressive bioepidemiologic profile, including familial patterns of inheritance $(5 \%-10 \%$ of cases), higher recurrence rates (12\%-22\%), and presentation at a younger age.

It is tempting to postulate that multiple lesions on initial presentation, as observed here, may predispose to local or distant recurrence. It would be interesting to determine

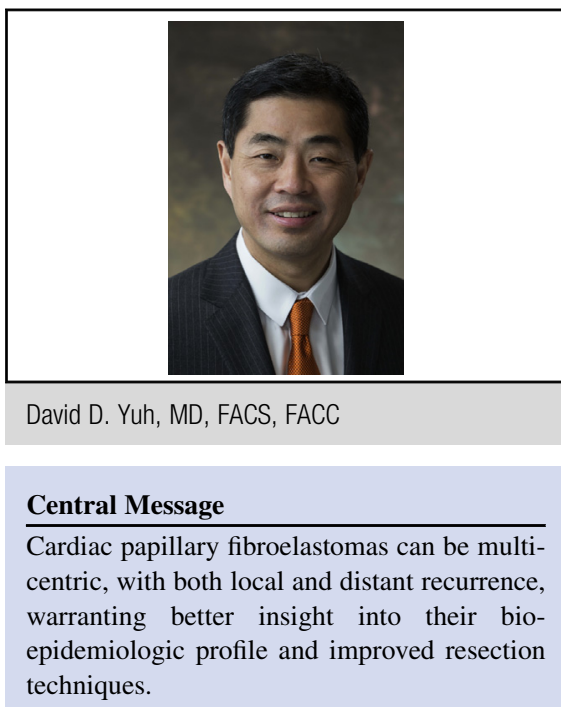

See Article page e125.

whether reported cases of recurrence were associated with multiple tumors at primary resection, as at least 1 of them was. ${ }^{7}$ Multiple tumors may be a manifestation of more aggressive proliferative behavior and may warrant more frequent postoperative echocardiographic surveillance. The association of multicentric tumors on initial presentation as a risk factor for recurrence has been reported with other neoplasms, including breast and papillary thyroid carcinoma. $^{8,9}$

Because incomplete resection has been implicated in local recurrence of both cardiac myxomas and papillary fibroelastomas, ${ }^{10}$ additional consideration to the surgical technique of resection, including valve-preserving methods and intraoperative frozen-section analysis to ensure complete resection, may be warranted. This case report suggests, however, that complete surgical extirpation of the primary tumor may still be inadequate in preventing distant recurrence, because the affected aortic valve was completely excised.

Although the risk of recurrence for the most common benign cardiac tumors remains very low, this case report illustrates that the morbidity of local or distant recurrence is significant and warrants more incisive investigation into their histopathologic behaviors and genomics to identify more aggressive subsets. Moreover, a closer look at developing techniques for ensuring complete resection of these tumors may further reduce recurrence rates. 


\section{References}

1. Grolla E, Dalla Vestra M, Zoffoli G, D'Ascoli R, Critelli A, Quatrale R, et al. Papillary fibroelastoma: a unique case of stroke in a young man. $J$ Cardiothorac Surg. 2017;12:33.

2. Ikegami H, Andrei AC, Li Z, McCarthy PM, Malaisrie SC. Papillary fibroelastoma of the aortic valve: analysis of 21 cases, including a presentation with cardiac arrest. Tex Heart Inst J. 2015;42:131-5.

3. Popovic C, Yong MS, Saxena P, Yadav S. Papillary fibroelastoma: a unique case of distant recurrence. J Thorac Cardiovasc Surg. 2019;157:e125-7.

4. Touati GD, Carmi D, Sevestre H, Poulain H. Multiple aortic valve papillary fibroelastoma: do not miss the other one. Eur J Cardiothorac Surg. 2002;21:596-7.

5. Gowda RM, Khan IA, Nair CK, Mehta NJ, Vasavada BC, Sacchi TJ. Cardiac papillary fibroelastoma: a comprehensive analysis of 725 cases. Am Heart J. 2003;146:404-10.
6. Bethea BT, Richter A. Primary cardiac tumors. In: Yuh DD, Vricella LA, Yang S, Doty JR, eds. Johns Hopkins Textbook of Cardiothoracic Surgery. 2nd ed. New York: McGraw Hill Professional; 2014:753-67.

7. Kammerer I, Besser R, Al-Azani M, Frank C, Bohrer MH, Sack FU. Fibroelastoma recurrence in left ventricle: rarity of primary cardiac tumor. Surg J. 2015;1:e35-7.

8. Neri A, Marrelli D, Megha T, Bettarini F, Tacchini D, De Franco L, et al. Clinical significance of multifocal and multicentric breast cancers and choice of surgical treatment: a retrospective study on a series of 1158 cases. BMC Surg. 2015;15:1.

9. Lin JD, Chao TC, Hsueh C, Kuo SF. High recurrent rate of multicentric papillary thyroid carcinoma. Ann Surg Oncol. 2009;16:2609-16.

10. Tamin SS, Maleszewski JJ, Scott CG, Khan SK, Edwards WD, Bruce CJ, et al. Prognostic and bioepidemiologic implications of papillary fibroelastomas. $J$ Am Coll Cardiol. 2015;65:2420-9. 